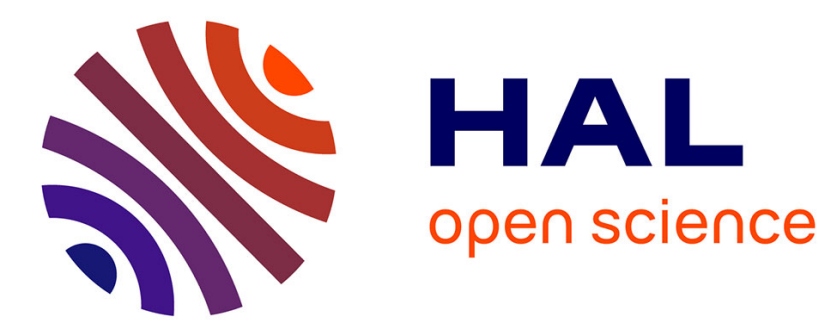

\title{
Flow property measurement for nanoimprint simulation
}

Tanguy Lévéder, Stéfan Landis, Laurent Davoust, Nicolas Chaix

\section{To cite this version:}

Tanguy Lévéder, Stéfan Landis, Laurent Davoust, Nicolas Chaix. Flow property measurement for nanoimprint simulation. Microelectronic Engineering, 2007, 84 (5-8), pp.928-931. 10.1016/j.mee.2007.01.065 . hal-00266796

\section{HAL Id: hal-00266796 \\ https://hal.science/hal-00266796}

Submitted on 29 Jan 2020

HAL is a multi-disciplinary open access archive for the deposit and dissemination of scientific research documents, whether they are published or not. The documents may come from teaching and research institutions in France or abroad, or from public or private research centers.
L'archive ouverte pluridisciplinaire HAL, est destinée au dépôt et à la diffusion de documents scientifiques de niveau recherche, publiés ou non, émanant des établissements d'enseignement et de recherche français ou étrangers, des laboratoires publics ou privés. 


\title{
Flow property measurements for nanoimprint simulation
}

\author{
T. Leveder ${ }^{\mathrm{a}, *}$, S. Landis ${ }^{\mathrm{a}, *}$, L. Davoust $^{\mathrm{b}}$, N. Chaix ${ }^{\mathrm{c}}$ \\ ${ }^{a}$ CEA Leti-Minatec, 17 rue des martyrs, 38054 Grenoble, France \\ ${ }^{\mathrm{b}}$ LEGIIENSHMG, 1025 rue de la piscine Dom. Univ. BP 53, 38041 Grenoble, France \\ ${ }^{\mathrm{c}}$ CNRS-LTM, 17 rue des martyrs, 38054 Cedex 9, Grenoble, France
}

\begin{abstract}
Number of recent works report that viscoelastic properties of ultra-thin polymer film (below $100 \mathrm{~nm}$ ) could drastically change from bulk values, deeply impacting nanoimprint process simulation. A good knowledge of thin resist film viscosity is thus needed, either for UV imprint, or thermal imprint. Nanoimprint lithography has been used to characterize sub $100 \mathrm{~nm}$ resist film flow properties above glass transition temperature. Specifically designed stamps have been manufactured to control silicon etched lines motion into the melt polymer. Adapted fluid modelling is proposed to calculate dynamic viscosity of thin polymer film for different temperatures from experimental data. Good agreements between ours results and literature were found.
\end{abstract}

Keywords: Nanoimprint lithography; Thermal imprint; Flow properties

\section{Introduction}

Nanoimprint lithography [1] is a powerful nanopatterning method. Nevertheless, it still remains a very empirical process: a viscous polymer film has to conform to a stamp applied under pressure. Detailed resist flow analysis is complicated, due to viscoelastic behaviour of polymer [2], predominance of capillary effects at nanoscale [3] and proximity effect of patterned areas [4]. Even though it is easier to pattern thick resist layer (over $1 \mu \mathrm{m}$ ) [5], residual thickness has to be reduced to ease patterns transfer via etching process. Therefore, nanoimprint is currently performed on sub $100 \mathrm{~nm}$ resist layer. However, thinner resist film implies that imprint process becomes even more sensitive to polymer viscosity.

As a consequence, the dynamical viscosity of ultra-thin resist layer appears to be a significant technological parameter for nanoimprint. It is the mechanical key parameter for printability [5] and process simulations [6]. Indeed, many

\footnotetext{
${ }^{*}$ Corresponding authors.

E-mail addresses: tanguy.leveder@cea.fr (T. Leveder), slandis@cea.fr (S. Landis).
}

publications have already demonstrated that many bulk material properties are drastically modified at nanoscale, like optical index [7] or glass transition temperature [8]. Due to higher confinement effects and polymer conformation modifications, viscosity of thin polymer layers will also greatly differ from bulk value. Recently, two approaches have been carried out so as to quantify film thickness dependency on viscosity.

The first one is dedicated to polymers and based on spontaneous growing of spinodal holes into supported polymer layer $[9,10]$. However, these results cannot be pertinently applied to imprint lithography issues. Indeed, we could not assume that supported and confined polymer layers will present identical viscous properties, since it has already been shown that free surface of supported films deeply impact on physical properties of thin layer [11].

The second approach has been used to investigate confined materials with atomic force microscope (AFM) measurement [12-14]. Confinement is thus obtained between the underneath substrate and AFM tip. Nevertheless, due to the tip sharpness, this method may be used only for very low viscosity material, like water or glycerol. Considering dimensions and materials used in nanoimprint process, a 
more suitable viscosity measurement method has to be developed.

The main idea in our experiment is to take advantage of an optimized stamp design to measure viscosity of ultrathin (sub $100 \mathrm{~nm}$ ) confined polymer layer with a standard imprint process. We will first describe the theoretical background used to establish a relationship between the dynamic viscosity and the experimental process parameters. Then, we will give details about the required experimental conditions and results will be analysed.

\section{Modelling of the embossing process}

Our goal is to obtain a relationship between applied forces and viscosity. In this study, we will focus on resist flow modelling during imprint. Considering 1D pattern, i.e. infinite line length (Fig. 1), we are able to perform a two-dimensional modelling of the system (Fig. 2). One major assumption of this paper is to consider a very low resist flow velocity during the imprint. Therefore, lubrication theory to describe squeezing flow can be used. Basically, the Navier-Stokes momentum equation is reduced to an unsteady laminar flow problem [15], shear flow exhibiting, therefore, a parabolic axial component

$$
\left.u_{x}(x, z, t)=\gamma(x, t) \cdot \frac{z}{h(t)}-\frac{z^{2}}{h(t)^{2}}\right)
$$

where $u_{x}(x, z, t)$ is the horizontal velocity field component at position $x$ and $z$ and time $t, h(t)$ is the residual layer thickness below the imprint line at time $t$, and $\gamma(x, t)$ an unknown function of the horizontal coordinates and time. It should be noticed that $z$ is ranging from 0 to $h(t)$. The steady $2 \mathrm{D}$ continuity condition must also be satisfied

$\frac{\partial u_{x}}{\partial x}+\frac{\partial u_{z}}{\partial z}=0$

Integrating Eq. (2) on a finite volume defined by the substrate surface, the imprint line and the two planes at position $\pm x$ (Fig. 3) and considering that resist brought in this volume during $\mathrm{d} t$ by the silicon line vertical motion went out through the vertical plane located at $\pm x$, we obtained

$-x \cdot \frac{\partial h}{\partial t}=\int_{0}^{h(t)} u_{x}(x, z, t) \mathrm{d} z$

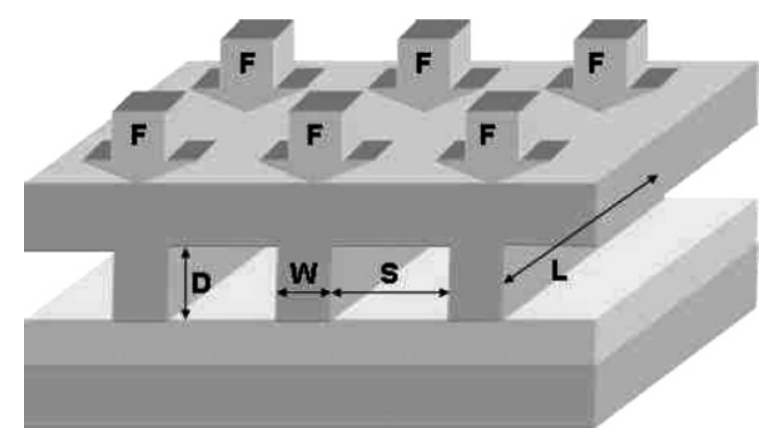

Fig. 1. Diagram of imprint and geometrical parameters definition.

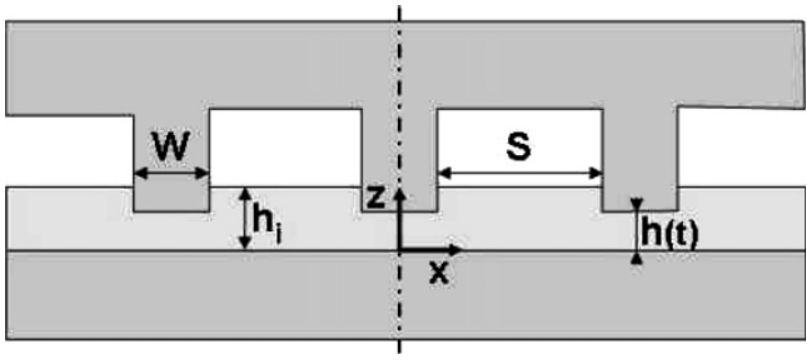

Fig. 2. Cross sectional profile of stamp motion into resist and residual layer thickness definition.

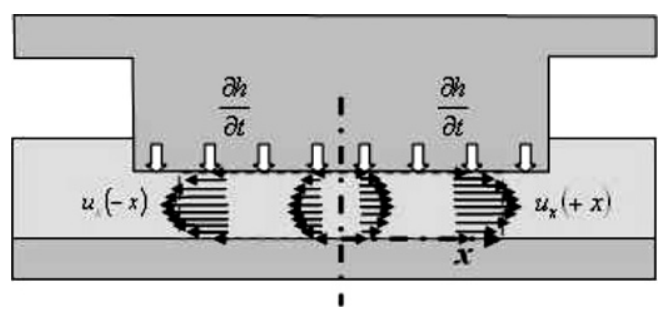

Fig. 3. Definition of the fictive volume for flow rate evaluation.

$\gamma(x, t)$ can thus be determined with Eq. (1):

$u_{x}(x, z, t)=-6 \frac{x}{h} \cdot \frac{\partial h}{\partial t}\left(\frac{z}{h}-\frac{z^{2}}{h^{2}}\right)$.

We have now a kinetic description of the whole horizontal flow underneath the imprinted line. Knowing the velocity flow, $x$ component of the Stokes equation establishes a relationship between the dynamic viscosity and the mechanical stress

$\frac{\partial P}{\partial x}=\mu \cdot\left(\frac{\partial^{2} u_{x}}{\partial x^{2}}+\frac{\partial^{2} u_{x}}{\partial z^{2}}\right)$.

Assuming that viscosity is a thickness dependent function, the pressure field $P$ underneath the imprinted line may be expressed as

$P(z=h)=6 \mu(h) \cdot \frac{\partial h}{\partial t} \cdot \frac{x^{2}-(W / 2)^{2}}{h^{3}}$.

By integration on the printed line surface, we obtain the unit reaction force of fluid on an imprinted pattern:

$F=-\mu(h) \cdot \frac{\partial h}{\partial t} \cdot \frac{W^{3}}{h^{3}} L$.

Finally, the equation of dynamic viscosity with respect to pattern sizes, applied force, resist thickness and vertical velocity of imprint is defined by

$\mu(h)=\frac{F}{\left(-\frac{\partial h}{\partial t}\right) \cdot \frac{W^{3}}{h^{3}} L}$.

\section{Experiments}

\subsection{Stamp design}

Imprints were performed on a full $200 \mathrm{~mm}$ wafer EVG $520^{\circledR}$ tool [4]. In order to determine viscosity field in the 
film, imprint velocity must be known. Nevertheless, as many tools, our experimental setup does not give the opportunity to measure the squeezing velocity in-situ. Therefore, we performed successive imprints and measured their depths to discretely determine the velocity as a function of time. The imprint conditions were chosen to have a slow enough motion of the stamp into the resist to be able to carry out several time steps.

It is well known in the nanoimprint community that in the first stage of an imprint (the local flow regime), resist is just disturbed at the pattern vicinity [2]. Polymer mounds appear at the pattern edges without any long-range effect. Large spaces between stamp lines were designed in order to free ourselves from complex polymer pattern growing. As a consequence, a large surface of resist film between lines is not printed. Therefore, imprinted depth can be determined with a profile measurement in the non imprinted and printed areas. Knowing initial resist thickness, absolute remaining thickness can obviously be obtained from this relative depth measurement.

To get appropriate imprint depths for the imprint velocity determination, line width and depth have still to be determined. From the order of magnitude of the viscosity given in the literature [7,8], and knowing the range of pressure allowed by our equipment, we design a line array stamp with $8 \mu \mathrm{m}$ periodicity $(S+W)$ and a $1 \mu \mathrm{m}$ $(W) \times 5.8 \mathrm{~mm}(L)$ line size (Fig. 1). The stamp depth $(D)$ is $500 \mathrm{~nm}$. By considering a dynamic viscosity $(\mu)$ of $1 \mathrm{MPa}$ s, an effective pressure of $1 \mathrm{MPa}$ and an initial resist thickness $\left(h_{\mathrm{i}}\right)$ of $100 \mathrm{~nm}$, this design is supposed to generate a squeezing velocity of about $1 \mathrm{nms}^{-1}$ which is fully compatible with our approach. Unit die is a square grating of 725 lines and 31 square dies have been prepared on a $200 \mathrm{~mm}$ silicon wafer stamp (Fig. 4).

\subsection{Methods of measurement and results}

Distribution of residual resist thickness across each die is measured by difference between local depth of patterned

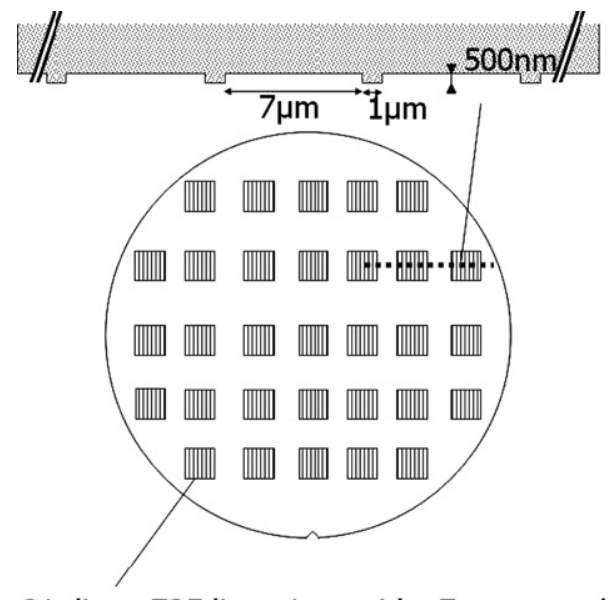

31 dies : 725 lines $1 \mu \mathrm{m}$ wide, $7 \mu \mathrm{m}$ spaced

Fig. 4. Stamp layout. lines and initial thickness of spin coated resist. Initial resist thickness has been measured by ellipsometry with a KLA Tencor 1280 set up. We spun coat Sumitomo NEB22 resist on a TEL MK8 track. NEB 22 is a PHS based negative tone resist, whose glass transition temperature is around $80^{\circ} \mathrm{C}$. Both 100 and $200 \mathrm{~nm}$ initial resist thicknesses have been considered for this study.

Distribution of imprinted depths across a die has been measured with a KLA Tencor HRP340 profilometer, with a vertical resolution of $0.7 \mathrm{~nm}$. As the printed line is $1 \mu \mathrm{m}$ width, a $20 \mathrm{~nm}$ horizontal scanning resolution has been chosen to get the lowest point reach by each line of the stamp. Consequently, the experimental data files were composed of $3 \times 10^{5}$ measurement points for each scan. This huge data files have been analysed with a home made $\mathrm{C}++$ software determining the printing depth below each line. The extracted value is averaged over several measured points and has been compared with atomic force microscopy measurements.

Fig. 5 shows the residual layer thickness $\left(h_{\mathrm{r}}\right)$ distribution across a die, below each printed line, for three different scanned positions with respect to the die edge. For the three scanned lines, $h_{\mathrm{r}}$ distributions are very similar, indicating that printing is very uniform over a large surface within the die. Indeed, the mean value and standard deviation of $h_{\mathrm{r}}$ is $68.0 \pm 6.1 \mathrm{~nm}, 68.9 \pm 8.3 \mathrm{~nm}$ and $66.9 \pm 5.8$ $\mathrm{nm}$ for the lines scanned at 2,3 and $4 \mathrm{~mm}$, respectively. Nevertheless, given our design, $h_{\mathrm{r}}$ is strongly affected in a $1 \mathrm{~mm}$ ring near the die border, since it varies from $200 \mathrm{~nm}$ (initial resist thickness) to 60-70 nm. Except this border effect, $h_{\mathrm{r}}$ is very uniform over a large surface in the middle of the die. We henceforth call imprinted depth the uniform part of the profile depths.

Subsequently, to determine the imprint velocity, we have only considered the area where the residual layer thickness was almost constant, thus neglecting the border effect. Fig. 6 shows the evolution of the imprinted depth against the printing time for a $100 \mathrm{~nm}$-thick initial layer printed at 115 and $130^{\circ} \mathrm{C}$. That is to say from 35 to $50^{\circ} \mathrm{C}$ above the glass transition temperature, where thermoplastic behaviour is well settled, and viscous behaviour is clearly

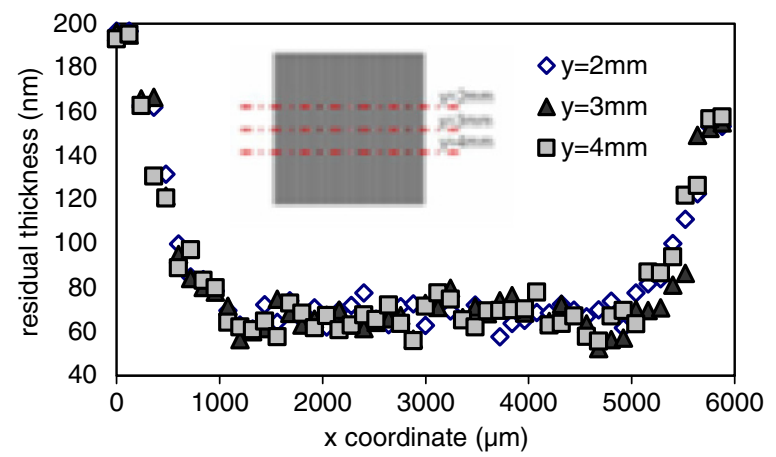

Fig. 5. Profile of imprinted depths across a die at three different positions A $200 \mathrm{~nm}$ resist layer has been imprinted at $130^{\circ} \mathrm{C}$ under 25 bar. To show a readable chart, only $7 \%$ of measurement points have been plotted. 


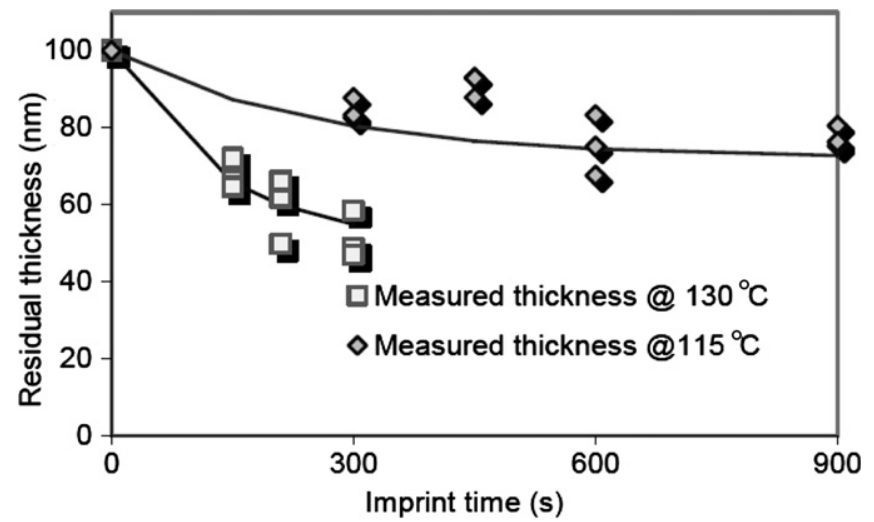

Fig. 6. Evolution of the imprinted depth as a function of imprint time for a $100 \mathrm{~nm}$ initial resist layer printed at 130 and $115^{\circ} \mathrm{C}$.

predominant on elastic behaviour. For each printed time, three depths have been determined from the three scans performed in one die, corresponding to $Y=2,3$ and $4 \mathrm{~mm}$.

From the time evolution of the printed depth, we calculate a discrete imprint velocity. Fig. 6 shows that an exponential law fits well with experimental data. Either from discrete differentiation of experimental data, or from differentiation of the exponential function, coherent trends are observed (Fig. 7). First, we have to notice that the obtained value for the imprint velocity in our experiment is in agreement with our calculation (see Section 3.1), meaning that the value of the dynamic viscosity is close to $1 \mathrm{MPa}$ s. If imprinted velocity would be $1 \mathrm{~nm} \mathrm{~s}^{-1}$, the calculated viscosity would be $1 \mathrm{MPa}$. Since velocity is below $1 \mathrm{~nm} \mathrm{~s}^{-1}$, viscosity is obviously higher than $1 \mathrm{MPa}$ s. Using Eq. (8) and data from Figs. 6 and 7, the dynamic viscosity for confined thin layer of NEB22 resist can be calculated. For a $85 \mathrm{~nm}$ thin resist layer the dynamic viscosity at $T_{\mathrm{g}}+35^{\circ} \mathrm{C}$ is about $1 \times 10^{8} \pm 9.5 \times 10^{6} \mathrm{~Pa}$ s and falls to $1 \times 10^{7} \pm 8 \times 10^{5} \mathrm{~Pa}$ s at $T_{\mathrm{g}}+50^{\circ} \mathrm{C}$. As expected the viscosity is reduced when the imprint temperature is increased.

We can notice that the order of magnitude of viscosity measured at nanoscale is higher than the macroscopic viscosity of similar molecular weight polymers. However, our results are very close to viscosity measurements of other spin coated resists [9].

\section{Conclusion}

Imprints have been performed with different imprint times and temperatures. By a suitable rheological model and stamp design, we have demonstrated that resist dynamic viscosity could be calculated. Our measurement method could provide constitutive behavior law necessary

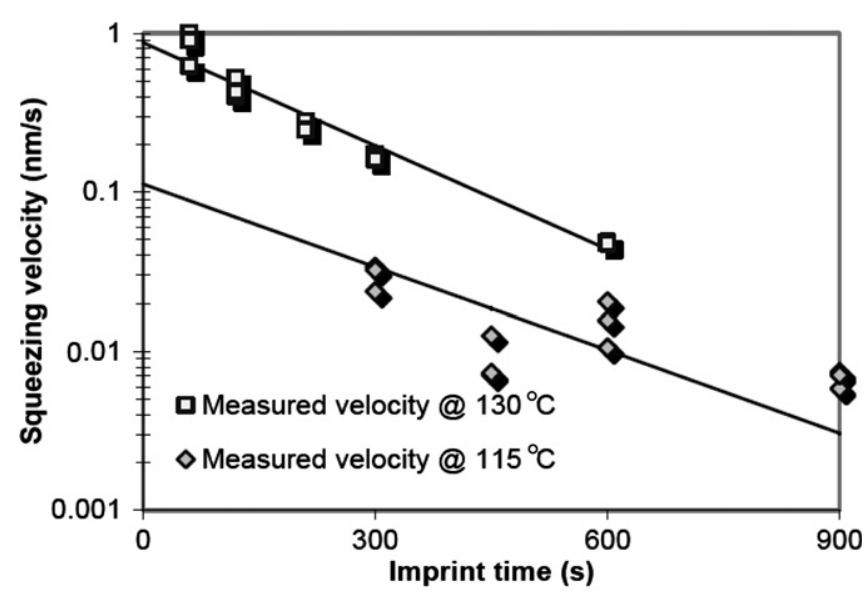

Fig. 7. Evolution of the imprint velocity as a function of time for a $100 \mathrm{~nm}$ resist layer printed at 115 and $130^{\circ} \mathrm{C}$.

to implement process simulations which lacks of fine knowledge of nanometer scale effect onto resist properties. Our results are in good agreement with already published data onto similar systems. Further experiments are under way to determine the process parameters impact (temperature, film thickness ...) on the resist viscosity behaviour.

\section{References}

[1] S.Y. Chou, P.R. Krauss, P.J. Renstrom, Appl. Phys. Lett. 67 (1995) 3114.

[2] T. Hoffmann, in: Kluwer Academic (Ed.), Alternative Lithography: Unleashing of the Potentials of Nanotechnology, Plenum Publisher, 2003 , p. 25 ;

H. Scheer, N. Bogdanski, M. Wissen, T. Konishi, Y. Hirai, Microelectron. Eng. 83 (2006) 843.

[3] S. Reddy, P.R. Schunk, R. T Bonnecaze, Phys. Fluids 12 (2005) 1.

[4] S. Landis, N. Chaix, C. Gourgon, C. Perret, T. Leveder, Nanotechnology 17 (2006) 2701.

[5] H. Schift, L. Heyderman, in: Kluwer Academic (Ed.), Alternative Lithography: Unleashing of the Potentials of Nanotechnology, Plenum Publisher, 2003, p. 47.

[6] D.-A. Mendels, Proc. SPIE 6151 (2006) 615113

[7] R. Swanepoel, J. Phys. E 16 (1983) 1214.

[8] K. Fukao, Y. Miyamoto, Phys. Rev. E 61 (2000) 1743.

[9] J.-L. Masson, P.F. Green, Phys. Rev. Lett. 65 (2002) 031806.

[10] C. Li, T. Koga, C. Li, J. Jiang, S. Sharma, S. Narayanan, L.B. Lurio, X. Hu, X. Jiao, S.K. Sinha, S. Billet, D. Sosnowik, Hyunjung Kim, J.C. Sokolov, M.H. Rafailovich, Macromolecules 38 (2005) 5144.

[11] J.S. Sharp, J.A. Forrest, Phys. Rev. Lett. 91 (2003) 235701.

[12] R.C. Major, J.E. Houston, M.J. McGrath, J.I. Siepmann, X.-Y. Zhu, Phys. Rev. Lett. 96 (2006) 177803.

[13] P.J. Febelmann, Langmuir 22 (2006) 2136.

[14] A. Mechlera, B. Piorek, R. Lal, S. Banerjee, Appl. Phys. Lett. 85 (2004) 3881.

[15] G.K. Batchelor, An Introduction to Fluid Dynamics, twelfth ed., Cambridge University Press, 1967, p. 179. 